\title{
ST. FRANSISKUS XAVERIUS: MISIONARIS, TELADAN IMAN DAN GURU BAGI MASYARAKAT KATOLIK
}

\author{
ST. FRANCIS XAVIER, MISSIONARY, EXAMPLE OF \\ THE FAITH AND TEACHER OF CHATOLIC COMMUNITY
}

\author{
Adison Adrianus Sihombing ${ }^{1}$ dan Masmedia Pinem ${ }^{2}$ \\ ${ }^{12}$ Badan Penelitian dan Pengembangan dan Pendidikan dan Pelatihan, \\ Kementerian Agama Republik Indonesia \\ sonadi2017@gmail.com
}

DOI: 10.31291/jlka.v19.i2.887

Diterima: 15 September 2021; Direvisi: 15 Desember 2021;

Diterbitkan: 31 Desember 2021

\begin{abstract}
Every society has a role model, because folklore is always related to a particular society. This study aims to elaborate and actualize the religious values that have been exemplified by St. Fransiskus Xavier in Maluku religious folklore. This study is based on qualitative research with a descriptive approach. Data collection techniques through observation, interviews, and documentation studies. The process of data analysis was carried out with data collection, data display, data reduction, and conclusion drawing. The results showed that the example of faith and personal qualities of St. Francis Xavier as a missionary who laid the foundations of Christianity in Maluku was very meaningful for the people of Maluku because it had changed their lives to know and believe in God. Therefore, this story is passed down from generation to generation so that it continues to be present in the public's memory. This folklore teaches the noble values that have been exemplified by Francis, namely being religious, generous, simple, hardworking and faithful in faith. His life example gives a message that people who live close to God will be a blessing to others.
\end{abstract}

Keywords: Religion, Fransiskus Xaverius, Missionary, Maluku. 


\begin{abstract}
ABSTRAK
Setiap masyarakat memiliki panutan/tokoh, karena cerita rakyat selalu berkaitan tentang masyarakat tertentu. Studi ini bertujuan mengelaborasi dan mengaktualisasikan nilai-nilai religius yang telah diteladankan oleh St. Fransiskus Xaverius dalam folklor religi Maluku. Studi ini didasarkan pada penelitian kualitatif dengan pendekatan deskriptif. Teknik pengumpulan data melalui observasi, wawancara, dan studi dokumentasi. Proses analisis data dilakukan dengan data collection, data display, data reduction, dan conclusion drawing. Hasil penelitian menunjukkan bahwa teladan iman dan kualitas pribadi St. Fransiskus Xaverius sebagai seorang misionaris peletak dasar kekristenan di Maluku sangat bermakna bagi masyarakat Maluku karena telah mengubah hidup mereka menjadi mengenal dan beriman kepada Allah. Oleh karena itu cerita ini diwariskan secara turun temurun sehingga terus hadir dalam ingatan publik. Folklor ini mengajarkan nilai-nilai luhur yang telah diteladankan oleh Fransiskus, yakni religius, murah hati, sederhana, kerja keras dan setia dalam iman. Teladan hidupnya memberi pesan bahwa orang yang hidup dekat dengan Tuhan, akan menjadi berkat bagi orang lain.
\end{abstract}

Kata kunci: Religi, Fransiskus Xaverius, Misionaris, Maluku.

\title{
PENDAHULUAN
}

Tradisi lisan adalah sama tuanya dengan sejarah kemanusiaan, bahkan ia telah ada sebelum manusia mengenal tulisan. Salah satunya adalah cerita rakyat ${ }^{1}$. Implikasinya sampai saat ini, di beberapa daerah tradisi lisan masih lebih dominan dibanding tradisi tulisan. Sebagai contoh dalam masyarakat Maluku. Masyarakatnya beragam adat-istiadat, suku, bahasa dan agama menyimpan banyak kekayaan budaya. Salah satunya adalah folklor religi. Masyarakat selalu melibatkan cerita rakyat pada berbagai keadaan dalam praktik hidup keseharian ${ }^{2}$. Pada zaman-

${ }^{1}$ Nikmah Sari Hasibuan, Irman Puansyah, and Ahmad Yamin Hasibuan, "Anthropos: Jurnal Antropologi Sosial Dan Budaya (Journal Analisis Cerita Rakyat Mandailing 'Sampuraga': Suatu Kajian Pendekatan Objektif Dan Nilai Pendidikan Karakter Analysis of Mandailing Folklore "Sampuraga": A Study of the Objective Approach An" 5, no. 2 (2020): 22235.

${ }^{2}$ Juliarti Trisni Andayani, Puspitawati, "ANTHROPOS : Jurnal Antropologi Sosial Dan Budaya Upaya Menebarkan Nilai-Nilai Kebaikan Melalui 
nya folklor digunakan sebagai sarana untuk menyampaikan ajaran atau pesan-pesan tentang nilai, norma dan kearifan lokal. Bahkan cerita pun digunakan untuk membantu manusia menemukan jawaban sementara atas apa yang tak terpahami ${ }^{3}$. Folklor merupakan bentuk karya sastra lisan yang lahir dan berkembang dalam masyarakat tradisional, dan disebarkan dalam bentuk relatif tetap dan tersebar di antara kelompok tertentu dalam waktu yang cukup lama ${ }^{4}$.

Maluku mempunyai kekayaan sastra seperti folklor religi yang dapat digunakan sebagai sarana pembelajaran hidup. Mengingat dalam perjalanan sejarah Maluku pernah menjadi tempat perdagangan dunia. Cerita rakyat sebagai salah satu warisan budaya menyimpan berbagai misteri, berupa sejarah dan nilai-nilai masa lalu yang harus digali dan diperhitungkan eksistensinya ${ }^{5}$ Cerita rakyat bukan hanya dimanfaatkan sebagai penyampai pendapat, ide dan nilai-nilai bahkan dapat juga dimanfaatkan untuk pemahaman informasi kepada orang lain, menyimpan, dan mewariskan gagasan dan nilai-nilai tersebut dari generasi ke generasi berikutnya ${ }^{6}$.

Salah satu cerita rakyat religi dari Maluku adalah Santo Fransiskus Xaverius. Cerita rakyat ini sangat dikenal dan terus hadir dalam ingatan masyarakat, secara khusus dalam komunitas orang Katolik hingga saat ini. Ia dikenal sebagai seorang misionaris peletak dasar kekristenan di pulau rempah-rempah tersebut. Hal yang paling melekat dalam ingatan masyarakat Maluku

Pelatihan Mendongeng Bagi Siswa / I Sekolah Dasar Di Kecamatan Percut Sei Tuan" 3, no. 1 (2018): 61-68.

${ }^{3}$ H. Geurtjens MSC, Legenda-Legenda, Terjemahan C.J. Bohm, MSC (Yogyakarta: Sibuku Media, 2015), iv.

${ }^{4}$ James Danandjaja, Folklor Indonesia: Ilmu Gosip, Dongeng, Dan Lain-Lain (Jakarta: Grafit, 1984), 50.

${ }^{5}$ Larlen Desi, Yundi, “Analisis Unsur Instrinsik Cerita Rakyat Sigindo Kuning Dusun Tuo Merangin Jambi," FKIP Universitas Jambi, no. 5 (2018): $7-21$.

${ }^{6}$ Nina Siti Salmaniah Siregar Syukria, "Buku Cerita Si Kancil Dan Perilaku Meniru Siswa Taman Kanak-Kanak Syukria," Jurnal Seni Dan Budaya 2, no. 2 (2018): 90-102, http://jurnal.unimed.ac.id/2012/index.php/ GDG. 
adalah Fransiskus sangat dihormati oleh semua orang karena kata-kata dan perbuatannya terutama karena seluruh sikap dan keunggulan pribadinya. Dalam hal ini dia memiliki suatu anugrah istimewa, yang membuat orang sangat mudah mengikuti dia. Ia hidup penuh keutamaan seperti orang saleh ${ }^{7}$. Hidup dari derma, sabar, baik hati kepada semua orang, dihormati dan dipandang sebagai orang suci. Sayangnya, cerita rakyat ini diwariskan secara turun temurun dengan tradisi lisan. Akibatnya terbatas orang yang dapat mengetahuinya dan generasi muda bangsa Indonesia juga kurang mengenal folklor Nusantara. Dalam konteks ini maka perlu sekali menyediakan sumber-sumber bacaan tentang cerita rakyat agar dikenal dan dicintai masyarakat ${ }^{8}$

Literatur yang ada tentang cerita rakyat cukup terbatas sehingga khazanah nilai-nilai luhur, yakni religi, moral, budaya, etika, sosial yang terkandung di dalamnya tidak dapat diakses masyarakat luas. Umumnya mereka mewariskan folklor melalui tradisi lisan (tutur) ke setiap generasi ${ }^{9}$. Nilai-nilai tersebut sangat dibutuhkan dalam kehidupan modern ini sebagai fondasi dalam membangun kehidupan bersama. Beberapa literatur yang ada, studi yang dilakukan oleh Hasibuan, $\mathrm{dkk}^{10}$ tentang cerita rakyat Mandailing "Sampuraga" yang secara jelas menganjurkan percaya kepada Allah dan melaksanakan salat lima waktu. Selain itu juga mengajarkan kasih sayang, kerja keras, dan kejujuran juga menunjukkan pentingnya mengkaji cerita rakyat untuk menemukan kearifan lokal dan memperkuat identitas masyarakat Kota

${ }^{7}$ Pr M.P.M. Muskens, Sejarah Gereja Katolik Indonesia-Umat Katolik Awal Mula Abad XIV - XVIII, 1st ed. (Ende-Flores: Arnoldus, 1974), 207.

${ }^{8}$ Toni Masdiono Agus Dody Purnomo, "Menggali Khasanah Tradisi Lisan Ke Dalam Medium Visual,” UNS, 2019, 47-54, https://docplayer. info/ 171730949-Menggali-khasanah-tradisi-lisan-ke-dalam-medium-visual.html.

${ }^{9}$ Agus Dody Purnomo, 47-54.

${ }^{10}$ Hasibuan, Puansyah, and Hasibuan, “Anthropos : Jurnal Antropologi Sosial Dan Budaya ( Journal Analisis Cerita Rakyat Mandailing ' Sampuraga ' : Suatu Kajian Pendekatan Objektif Dan Nilai Pendidikan Karakter Analysis of Mandailing Folklore " Sampuraga ": A Study of the Objective Approach An," 225-35. 
Langsa sebagai masyarakat yang plural ${ }^{11}$. Berbeda dengan studi, cerita rakyat Sunda sebagai sumber ide, kekayaan budaya yang dapat digunakan sebagai medium visual untuk buku seni. ${ }^{12}$ Ada juga literatur yang menunjukkan cerita rakyat suku Pasemah Bengkulu sebagai sumber belajar tentang nilai untuk pendidikan karakter dalam materi pembelajaran sastra. Ditunjukkan bahwa dalam cerita rakyat dapat ditimba nilai-nilai luhur kehidupan: sosial, disiplin, rendah hati, religius, berani, tanggungjawab, cerdik, sabar, patuh, optimis, kerjakeras, ikhlas, menerima kekalahan menepti janji, cinta tanah air, cinta kebangsaan, menghargai prestasi, ingin tahu, dan bersahabat ${ }^{13}$. Dari literatur yang ada, sejauh ini studi khusus cerita rakyat religi masyarakat Indonesia belum terpetakan dan luput dari perhatian para akademisi. Dalam konteks ini studi cerita rakyat keagamaan menemukan relevansinya. Adanya keterbatasan buku bacaan cerita rakyat keagamaan menjadikan studi ini menjadi penting sekaligus menemukan kebaruannya dalam rangka menjaga kelestarian warisan nenek moyang.

Sebagaimana diungkapakan oleh Thompson $^{14}$ segi-segi yang perlu dicermati oleh seorang peneliti tradisi lisan mencakup lima hal sebagai berikut: (1) deskripsi mengenai sumber tradisi lisan tersebut; kebiasaan penuturan dan bagaimana peneliti mendapatkan teks itu, (2) makna cerita tersebut; apakah sesuai dengan ekspresi linguistiknya ataukah memiliki makna cerita tersembunyi (hidden significance), (3) penyebaran cerita rakyat itu; sidat-sidat penyebarannya, mengapa terjadi penyebaran, (4) variasi-variasi teks; apakah setiap variasi teks berdiri sendiri,

${ }^{11}$ Riyani Mufti, Ramazan, "Kearifan Lokal Dalam Folklor Asal Usul Kota Langsa," REFLEKSI EDUKATIKA 11, no. 1 (2020): 88-95, https://doi. org/http://jurnal.umk.ac.id/index.php/RE.

${ }^{12}$ Agus Dody Purnomo, "Menggali Khasanah Tradisi Lisan Ke Dalam Medium Visual," 47-54.

${ }^{13}$ Fitra Youpika and Darmiyati Zuchdi, "Nilai Pendidikan Karakter Cerita Rakyat Suku Pasemah Bengkulu Dan Relevansinya Sebagai Materi Pembelajaran Sastra," Jurnal Pendidikan Karakter, no. 1 (2016): 48-58, https://doi.org/10.21831/jpk.v0i1.10731.

${ }^{14}$ Kenneth Thompson, "FOLKLORE AND SOCIOLOGY" 28, no. 2 (1980): 249-75. 
bagaimana sifat-sifat penyebarannya dan mengapa terjadi perbedaan versi tersebut, dan (5) relevansi cerita itu dengan ceritacerita lainnya seperti sage, mitos, epos, legenda, dan sebagainya. Tradisi lisan, termasuk folklor keagamaan Maluku, merupakan warisan budaya nasional dan masih mempunyai nilai-nilai berharga yang perlu dikembangkan dan dimanfaatkan untuk kehidupan masa kini dan masa depan. Di antaranya dalam hubungan dengan usaha pembinaan apresiasi sastra, penciptaan karya baru, dan pembinaan komunikasi antara pencipta dan masyarakat.

Dewasa ini, informasi tentang sastra lisan daerah belum banyak diketahui dengan lebih pasti. Hal ini disebabkan oleh kurangnya penelitian tentang sastra lisan ${ }^{15}$ mengklasifikasikan tradisi lisan ke dalam tiga bentuk: tradisi lisan, setengah lisan, dan bukan lisan. Finnegan membagi bentuk tradisi lisan ke dalam jenis puisi lisan, yaitu meliputi nyanyian anak-anak, epik, lirik, balada dan puji-pujian ${ }^{16}$. Dalam folklor Indonesia folklor lisan dibagi dalam kelompok besar yang berupa (a) bahasa rakyat (folk speech), logat, julukan, pangkat tradisional, dan titel kebangsawanan, (b) ungkapan tradisional, seperti peribahasa, pepatah, dan pemeo, (c) pertanyaan tradisional seperti tekateki, (d) puisi rakyat, seperti pantun, gurindam, dan syair, (e) cerita prosa rakyat, seperti mite, legenda dan dongeng, dan (f) nyanyian rakyat. ${ }^{17}$ Secara commond-sense folklor merupakan memori kolektif suatu kelompok masyarakat yang disebarkan dan diwariskan pada masyarakat yang pernah hidup di masa lalu. Dapat dikatakan folklor sebagai media untuk memahami wawasan, cara berpikir, sumber pengetahuan masa lampau dan pola tindakan para leluhur di masa terdahulu. Dengan demikian bentuk formal tradisi lisan tidak pernah stabil dan sarana-sarana kesastraan sering kali berubah-ubah sesuai dengan motif penceritaannya.

Studi ini bertujuan untuk mengelaborasi dan mengaktuali-

${ }^{15}$ Mohammad Kanzunnudin, “CERITA LISAN DUA ORANG SUNAN BERADU JAGO DALAM KAJIAN STRUKTURAL DAN FUNGSI ALAN DUNDES," Bahasa Dan Sastra 3, no. 2 (2020): 235-48.

${ }^{16}$ Ruth Finnegan, Oral Literature in Africa . (Cambridge: Open Book Publishers, 2012), 229-37.

${ }^{17}$ Danandjaja, Folklor Indonesia: Ilmu Gosip, Dongeng, Dan LainLain, 238. 
sasikan nilai-nilai religius yang telah diteladankan oleh St. Fransiskus Xaverius dalam folklor religi Maluku. Selain itu, juga dimaksudkan untuk mengembangkan tradisi tulisan sebagai tindakan konkret untuk melestarikan warisan budaya agar tidak punah sekaligus melengkapi kebutuhan literatur cerita rakyat religi. Dengan demikian warisan nilai-nilai luhur kehidupan yang telah diteladankan sang tokoh lewat kualitas pribadi, sikap dan karakternya dapat terungkap dan diketahui publik. Cerita rakyat sebagai karya sastra sarat akan pesan, didalamnya terkandung suri teladan, nilai falsafah, nilai pendidikan, nilai moral, nilai etika, yang bermanfaat bagi pembangunan bangsa ${ }^{18}$. Dengan demikian studi ini berkontribusi agar semakin banyak orang yang mengetahui sekaligus menjadi sumber tertulis sebagai sarana pembelajaran nilai bagi generasi muda. Sejalan dengan itu maka dirumuskan tiga pertanyaan dijawab dalam studi ini. Pertama, siapa Fransiskus Xaverius dan bagaimana caranya mewartakan Injil di Maluku? Kedua, nilai-nilai apa saja yang telah diteladankan Fransiskus Xaverius di Maluku? Ketiga, Faktor-faktor apa saja yang membuat Fransiskus mudah diterima semua orang di Malaku? Jawaban atas ketiga pertanyaan tersebut menjadi pokok bahasan dalam artikel ini. Tulisan ini didasarkan pada tiga argumen, yakni Fransiskus Xaverius adalah misionaris Katolik peletak dasar iman kekristenan di pulau rempah-rempah. Nilainilai luhur kehidupan yang telah ditaburkan telah bertumbuh, berkembang dan berbuah. Kemampuan melakukan hal-hal yang luar biasa, teladan hidup, kualitas pribadi dan karakternya yang kuat menjadi faktor pendukung sehingga Fransiskus berhasil dan mudah diterima oleh masyarakat Maluku.

Studi ini didasarkan pada penelitian kualitatif dengan pendekatan deskriptif. Teknik pengumpulan data melalui observasi, wawancara, dan studi dokumentasi. Proses analisis data dilaku-

${ }^{18} \mathrm{M}$ zikri Wiguna and A A Alimin, “Analisis Nilai-Nilai Moral Dalam Cerita Rakyat Kalimantan Barat," Jurnal Pendidikan Bahasa 7, no. 1 (2018): 143-58, http://journal.ikippgriptk.ac.id/index.php/bahasa/article/view/833. 
kan dengan menggunakan model analisis interaktif ${ }^{19}$, yaitu data collection, data display, data reduction, dan conclusion drawing. Penelitian dilakukan di daerah Ambon - Maluku pada bulan Juni tahun 2019. Narasumber penelitian adalah Pastor Misionaris di Maluku, dosen Sekolah Tinggi Pastoral Katolik Santo Yohanes Penginjil Ambon, Kepala Balai Bahasa Maluku, Dosen IAIN Ambon, penyuluh agama dan tokoh masyarakat. Data utama diperoleh melalui wawancara narasumber dan pengamatan dengan setting natural. Data sekunder dari laporan, buku, dan jurnal. Teknik analisis data yang digunakan dengan cara data diklasifikasi, diolah, dianalisis lalu disimpulkan.

\section{HASIL DAN PEMBAHASAN}

\section{Misi Katolik di Ambon-Maluku oleh Fransiskus Xaverius ${ }^{20}$}

Ketika Paus Alexander VI pada tahun 1493 mengambil kebijakan membagi dunia baru antara Spanyol dan Portugis mensyaratkan bahwa raja-raja harus memajukan Misi Katolik Roma di daerah-daerah yang telah diserahkan kepada mereka. Tuntutan ini mendorong raja-raja melakukan ekspansi ke berbagai daerah sembari membawa pekabaran injil, Namun, pembagian dunia ini menjadi persoalan tersendiri bagi kedua negara tersebut karena terjadi perebutan Maluku kepulauan rempahrempah masuk dalam wilayah Portugis atau Spanyol. Para ahli bumi kedua negara tersebut terus berkonflik. Permulaan Misi di Maluku pada tahun 1522 yang dibawa oleh orang Portugis ke daerah Tidore, Ternate, kepulauan-kepulauan kecil, Hitu di Ambon, Leitimor, kepulauan Seram, dan buru. Penduduknya masih hidup dalam agama nenek moyang. Orang Portugis me-

${ }^{19}$ A. Michael Huberman, Matthew B. Miles, and J Saldana, Qualitative Data Analysis, A Methods Source Book, 3rd ed. (USA: SAGE Publications, Inc., 2014), 71-90.

20.Disaripatikan dari M.P.M. Muskens, Pr, 1974. Sejarah Gereja Katolik Indonesia - Umat Katolik Awal Mula abad XIV - XVIII, Ende-Flores: Arnoldus, hlm. 200-207; Schumann, Olaf. 2017. Kekristenan di Asia Tenggara, Jakarta: BPK Gunung Mulia, hlm. 22-24; Berkhof, H.1950. Sejarah Gereja. Disadur untuk Indonesia oleh Enklaar, I.H. 2019. Jakarta: BPK Gunung Mulia, hlm. 235-237. 
nyebarluaskan iman Katolik kepada penduduk yang ada di daerah-daerah tersebut. Awalnya pilihan menjadi Katolik merupakan pilihan politis, persahabatan antara orang Portugis dengan Sultan Ternate. Siapa misionaris yang pertama di Maluku tidak tercatat dengan baik, tetapi yang pasti ada seorang pastor menetap di Ternate yang bertugas pertama-tama mengurus kepentingan rohani umat Katolik Portugis. Selain itu ada juga beberapa misionaris rahib Fransiskan pada tahun 1522, tetapi misi mereka gagal karena terjadi perselisihan antara orang Portugis dengan penduduk setempat.

Setelah kekuasaan Portugis terbentuk di Maluku beberapa misionaris Fransiskan ditugaskan di sana. Tahun 1546 Seorang misionaris terbesar dalam sejarah Gereja tiba di Ambon, bernama Fransiskus Xaverius. Ia lahir tahun 1506 berasal dari sebuah keluarga bangsawan tua dari wilayah Navarra, Spanyol. Atas permintaan raja Portugal dan Paus maka pada tahun 1541 ia berangkat ke Asia Timur. Kelak misionaris Yesuit yang masyhur, Fransiskus Xaverius dikenal sebagai perintis Misi di Timur Jauh (1542 -1552) atau pembuka jalan bagi Misi Katolik Roma dan peletak dasar Gereja Katolik Roma di India, Malaka, Maluku dan Jepang. Xaverius tiba di Ambon pada bulan Februari 1546. Ia juga mengunjungi Ternate, Halmahera, dan Morotai. Ketika Fransiskus tiba di Amboina, ia menemukan orang-orang Katolik yang ada di tujuh (Hatiwi, Amantelo, Nusaniwi, Hukunalo, Tawiri, Leitimor, Halong) kampung kristen terlantar kehidupan rohani mereka karena imam yang mempermandikan dan memelihara iman mereka telam lama meninggal dunia. Kehadiran Fransiskus menjadi sebuah kegembiraan tersendiri dan dia disambut dengan baik. 


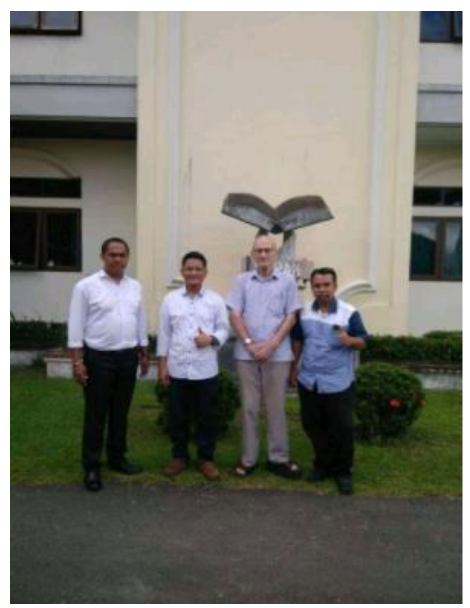

Gambar 1.

foto Juni 2019 bersama narasumber utama tentang St. Fransiskus Xaverius (Rm. Cornelis Johannes Bohm, MSC misionaris Belanda terakhir); dari kiri Yosi Dirwot (Penyuluh Agama Katolik Kota Ambon; Adison Sihombing dan Masmedia Pinem (peneliti).

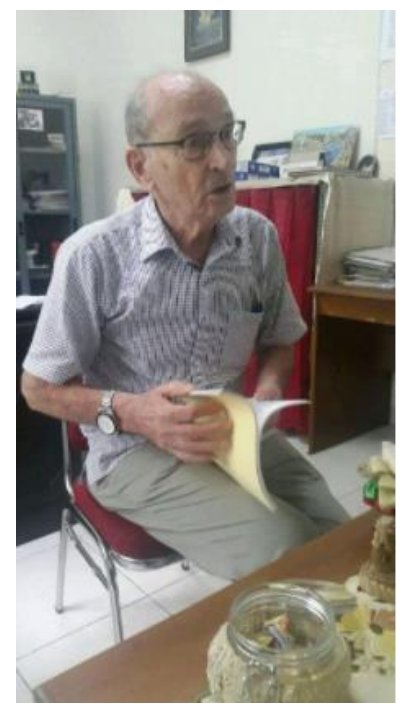

Gambar 2.

Wawancara dengan Rm. Cornelis Johannes Bohm, MSC dengan peneliti folklor religi pada bulan Juni 2019.

Selama lima belas bulan (Februari 1546 s/d Mei 1547) bekerja di Maluku, Xaverius telah membaptis ribuan orang. Xaverius berusaha agar jumlah misionaris yang bekerja di Maluku segera ditambah jumlahnya. Selain itu, ia juga menguatkan struktur hierarkis gereja. Mutu pendidikan katekumenis (orang yang mau dibaptis masuk Katolik) ditingkatkan. Ia membuat program pengajaran iman Katolik diberikan setiap hari kepada orang-orang yang akan dibaptis dan juga setelah mereka dibaptis, meminta mereka yang telah dibaptis agar memancangkan salib-salib besar dan patung-patung tokoh-tokoh suci Gereja Katolik di tempat-tempat umum, menganjurkan prosesiprosesi publik yang merupakan kebiasaan umat Katolik untuk menunjukkan kehadiran kepercayaan mereka juga di hadapan publik. Nyanyian-nyanyian Kristiani pun dikarang. Selain itu, katekismus dan pengakuan iman dipelajari juga. Ia menerjemahkan ajarannya ke dalam Bahasa Melayu. Berkat usaha dan jasajasanya dalam meletakkan dasar iman Katolik maka Fransiskus 
Xaverius diangkat menjadi Pelindung Gereja Katolik Indonesia. (Bdk. Schumann, Olaf. 2017. Kekristenan di Asia Tenggara, Jakarta: BPK Gunung Mulia, hlm. 22-24; Berkhof, H.1950. Sejarah Gereja. Disadur untuk Indonesia oleh Enklaar, I.H. 2019. Jakarta: BPK Gunung Mulia, hlm. 235-237.

\section{Ambon-Maluku: Lahan Subur untuk Rempeh-Rempah dan Pertumbuhan Iman}

Bangsa Indonesia kaya akan cerita rakyat yang diabadikan secara turun temurun dari mulut ke mulut hingga kini seperti dongeng, mitos, hikayat dan sebagainya ${ }^{21}$ Salah satunya adalah wilayah Maluku. Maluku salah satu pulau di bagian Indonesia timur dikenal sebagai negeri seribu pulau karena terdiri dari gugusan pulau-pulau, yaitu Seram, Buru, Maluku Tenggara, Saparua, Haruku, Ambon dan Nusa Laut ${ }^{22}$. Maluku memiliki dua kotamadya, yaitu Ambon dan Tual. Ambon merupakan ibukota provinsi Maluku. Maluku terkenal dengan sebutan Negeri Rempah-Rempah, karena banyaknya rempah-rempah yang tumbuh di daerah tersebut. Salah satunya yang terkenal pada zamannya adalah pala. Kekayaan rempah-rempah tersebut menjadi daya tarik yang kuat sehingga banyak negara datang ke Indonesia bahkan menjajah seperti Portugis, Spanyol, Belanda, dan Jepang.

Menurut narasumber dari Balai Bahasa Maluku, pada umumnya ketika orang mendengar kata "Ambon", maka secara spontan orang akan berkata: "Ambon manise". Ungkapan tersebut tepat bila ditelisik lebih dalam akan kandungan kekayaan baik di alamnya maupun dalam realitas kehidupan manusianya. Secara metaforis dapat dilukiskan adanya "rasa manis" (baca: kualitas terbaik di dunia) dari cengkeh pala membuat manusia

${ }^{21}$ Kanti Rahayu, “ARTI PENTING FOLKLORE DAN TRADITIONAL KNOWLEDGE BAGI INDONESIA SEBAGAI ' THE COUNTRY OF ORIGIN,"' media, 2000, 1-14, https://media.neliti.com/media/publications/ 241676-none-b4b826e4.pdf.

${ }^{22}$ Nita Handayani Hasan, Pelestarian Dan Pengembangan Mitos Ikan Lompa - Tinjauan Strukturlisme Levi Straus (Ambon: Kantor Bahasa Maluku Kementerian Pendidikan dan Kebudayaan, 2017), 2-4. 
dari berbagai belahan dunia berebut dan berlomba-lomba datang ke kepulauan Maluku. Pada saat itu fungsi utama cengkeh digunakan untuk mengawetkan makanan sehingga dapat bertahan lama ketika orang sedang dalam perjalanan jauh, pelayaran panjang dan lama. Oleh karena itulah kepulauan tersebut terkenal sebagai kepulauan rempah-rempah (Wawancara, 18 Juni 2019 di Kantor Balai Bahasa Maluku).

Kedatangan para pedagang dan bangsa asing termasuk misionaris Fransiskus Xaverius memberikan warna tersendiri dalam kehidupan sosial masyarakat maluku. Maluku merupakan salah satu provinsi di Indonesia yang memiliki ragam budaya, adat istiadat dan kearifan lokal. Sejarah kehidupan masyarakat Maluku pun semakin diperkaya dengan budaya, bahasa, agama dan penuh dengan dinamika. Menurut narasumber Balai Bahasa Maluku, Maluku lama belum ada tulisan zaman Belanda, karena pada masa Belanda berkuasa belum ada aksara. Ketiadaan aksara diisi oleh tradisi lisan. Karena itu cerita rakyat Maluku ada tersimpan dalam tradisi lisan yang disebut kapata. Kapata tentang semua kampung di Ambon dulunya ada dan diturunkan secara turun temurun secara lisan. Oleh sebab itu tidak jarang terdapat beberapa versi tentang cerita rakyat. Menurut narasumber ini, ketika ada berbagai versi maka terjadi perdebatan panjang. Padahal itu memperkaya. Sikap yang tepat sebaiknya semuanya harus dilestarikan dan dijaga serta dicari benang merahnya. Dengan demikian tradisi lisan itu tidak mati, dan banyak versi. Sementara tulisan tidak ada versi dan tidak ada perdebatan lagi. Dengan kata lain kita perlu menemukan fakta dalam cerita rakyat. Sayangnya saat ini kapata tersebut banyak yang hilang seiring dengan punahnya bahasa-bahasa daerah. Kematian bahasa daerah berdampak pada kematian sarana untuk penyampaian sejarah. Ketika bahasa daerah ini hilang maka tergeruslah cerita tentang kapata ini (Wawancara, 18 Juni 2019 Balai Bahasa Maluku \& 19 Juni 2019 IAIN Ambon).

Dalam konteks cerita rakyat, menurut narasumber ini Maluku belum banyak mempunyai sumber tertulis untuk pendidikan karakter anak Maluku. Dalam situasi ini Balai bahasa mengajak orang tua (penatua) untuk terbuka memberikan informasi. Sebab kematian orang tua adalah kematian perpustakaan. 
Orang tua yang mengetahui banyak hal tentang sejarah masa lalu adalah merupakan perpustakaan hidup, informan utama. Hal itulah yang terjadi dengan cerita misionaris peletak dasar iman di Maluku. Suri teladan, pekerjaan mulia, dan kualitas pribadi Fransiskus masih segar hadir dalam ingatan publik masyarakat Maluku secara khusus masyarakat Katolik. Sayangnya cerita Fransiskus hanya diturunkan secara turun temurun dengan tradisi lisan. Hal ini disebabkan tradisi lisan masih lebih dominan daripada tradisi tulisan di wilayah Maluku. Hal ini ditegaskan pula oleh narasumber dari Institut Agama Islam Negeri (IAIN) dalam kesempatan wawancara, Rabu 19 Juni 2019: "Orang Maluku kuat tradisi oral daripada tulisan". Artinya masyarakat Maluku lebih dominan menggunakan tradisi tuturan dalam mewariskan cerita-cerita rakyat. Banyak cerita rakyat yang dikenal dalam masyarakat Maluku termasuk tentang Fransiskus Xaverius. Cerita rakyat menjadi kekayaan dan kebanggan masyarakat Maluku yang dikenal sebagai kota beriman dengan beragam agama. sebutlah misalnya beberapa yang telah sangat dikenal orang sebagai kearifan local: orang hidup bersaudara, saling membantu karena ada hubungan keterikatan yang sangat kuat bahkan melebihi hubungan satu darah/keluarga. Jika ada yang sedang berduka atau berbahagia maka yang lain pun turut serta merasakannya. Hal ini dilukiskan dengan ungkapan: potong di kuku rasa di daging. Ale rasa beta rasa. Ini milik bersama. Ungkapan dalam bentuk melayu Ambon. Selain itu ada prinsip keadilan, sagu salempeng dibagi dua. Demikian juga dalam agama. Islam misalnya mengenal prinsip tidak beriman salah seorang di antara kamu hingga dia mencintai untuk saudaranya. Dalam Kristen dikenal cintailah sesamamu seperti dirimu sendiri. Dengan demikian setiap cerita rakyat itu mengalamai proses inkulturasi sesuai dengan masyarakat agama masing-masing. Selain itu cerita rakyat juga sekaligus memberikan wawasan sejarah dan budaya mereka (wawancara, 19 Juni 2019, IAIN Ambon).

Menurut narasumber dosen Sekolah Tinggi Pastoral Katolik Santo Yohanes Penginjil Ambon, Fransiskus datang ke Maluku sebagai misionaris pada zaman Portugis berkuasa. Dia 
fokus untuk mewartakan injil. Saat ini ketika orang berbicara atau mendengar nama Fransiskus Xaverius, maka hal yang pertama muncul dalam pikiran orang adalah sosok dia sebagai orang yang saleh, teladan iman, murah hati, sederhana, baik hati dan dicintai dan disenangi semua orang (wawancara, 19 Juni 2019). Selain kualitas pribadi Fransiskus yang kuat, juga dikenal lewat cara dia yang khas dan unik dalam melakukan pewartakan Injil ketika sedang berkunjung berkeliling ke kampung-kampung. Fransiskus selalu berjalan bersama rombongan bersama anak-anak, di depannya selalu ada anak yang membawa salib, sembari berjalan mereka menyanyikan lagu syahadat iman, doa Bapa kami, lalu Fransiskus bertanya apakah ada orang yang sakit untuk didoakan. Jika ada, maka Fransiskus masuk rumah, mengangkat tangan dan berdoa. Anak-anak yang menghantar dia mengucapkan doa syahadat (Credo) dan perintah-perintah Allah dalam bahasa Melayu. Fransiskus membacakan Injil untuk orang sakit atau mempermandikan anak-anak (wawancara, 19 Juni 2019).

Fransiskus mengumpulkan anak-anak, remaja, kaum muda, orang dewasa, lalu mereka diberi pelajaran agama, dilatih cara berdoa, lagu-lagu rohani seperti Credo, Bapa kami, Salam Maria, Perintah-perintah Allah, Karya-karya amal dan cinta kasih, Doa Tobat, dan kebenaran-kebenaran iman yang sudah diterjemahkan ke dalam bahasa Melayu. Fransiskus berdakwah atau mewartakan iman dengan cara damai, tanpa kekerasan ataupun paksaan. Ia hidup menyatu dengan masyarakat, hidup bersama masyarakat, dan bersahabat dengan semua orang. Hal ini membuat dia mudah diterima masyarakat dengan cepat. Dengan demikian kehadiran Fransiskus memberikan penghiburan dan menyenangkan bagi warga masyarakat. Fransiskus menyampaikan pesan kepada penduduk kampung sebagai tanda pengenal agama mereka yang baru itu, orang-orang Kristen memancangkan salib besar, dan pada malam hari mereka menyalakan obor dan berdoa di muka salib itu. Selain itu, Fransiskus selalu mengingatkan semua orang agar setia berpegang teguh pada imannya yang suci dan lebih baik mati daripada mengingkarinya (wawancara, 19 Juni 2019).

Metode pewartaan Fransiskus ini diafirmasi oleh nara- 
sumber pastor misionaris satu-satunya yang masih ada di Ambon. Metode Fransiskus yang khas dan unik membuat orang kampung dapat dengan mudah mengenal jika rombongan Fransiskus sedang lewat. (Wawancara, 19 Juni 2019). Metode mewartakan injil dengan menyanyikan syahadat iman "Credo", dan doa Bapa kami. Pada malam hari dia berkeliling dengan Manuel pembantunya, membawa lampu dan bel kecil (giringgiring) keliling kampung mengajak orang berdoa untuk orangorang dalam sakaratul maut, dan api pencucian. Fransiskus mendoakan: "Tuhan berikanlah aku jiwa-jiwa supaya aku bisa menyelamatkan" (Wawancara, 19 Juni 2019).

Menurut semua narasumber hal yang paling dikenal, paling diingat dan selalu diwariskan secara turun temurun cerita tentang Fransiskus Xaverius adalah pengalaman mukjizat yang dialami dan disaksikan orang pada masa itu. Pengalaman yang luar biasa itu menjadi bukti kuat bahwa Fransiskus adalah orang suci, orang yang sangat dekat dengan Tuhan. Pertama, ketika dalam sebuah pelayaran dari Amboina menuju Pulau Seram perahu Fransiskus dihempas ombak dan badai yang dahsyat. Para awak berusaha keras dengan dayung supaya lekas keluar dari tempat berbahaya itu. Fransiskus mengambil salib, yang tergantung dengan seutas tali di lehernya. Sebuah salib ukiran dari kayu sepanjang satu jengkal. Fransiskus mencelupkannya ke dalam laut yang bergelora itu sambil berdoa: "Semoga Allah berkenan membebaskan dari bahaya ini demi pahala putera-Nya tersalib." Tetapi tali itu putus, dan salib terlepas dari tangannya dan jatuh ke dalam laut. Pater Fransiskus sangat sedih. Sesampainya perahu itu berlabuh di pantai pulau Seram. Fransiskus bersama pengantarnya langsung menuju ke kampung Tamilau yang terletak di pinggir pantai. Mereka belum berjalan kaki selama sepuluh menit, tiba-tiba mereka melihat seekor udang besar merangkak ke luar dari ombak yang datang menuju tepi pantai, membawa salib itu dijepit pada taringnya lewat di depan Pater Fransiskus. Melihat itu, Fransiskus lantas berlutut, dan udang itupun berhenti, sampai dia mengambil salib itu, lalu udang itu kembali ke dalam laut lagi. Fransiskus mencium salib itu, lalu berlutut di situ selama hampir setengah jam, sambil memegang salibnya dan 
mendekapkannya pada dadanya. Cerita ini ada dua versi yang berkembang dalam masyarakat. Ada yang mengatakan yang membawa salib itu kepiting, ada juga yang mengatakan udang besar. Seperti yang telah diungkapkan pada bagian sebelumnya oleh narasumber dari Balai Bahasa Maluku. Adanya beberapa versi tentang sebuah cerita rakyat tidak perlu diperdebatkan. Yang terpenting adalah ditemukan nilai, makna dan pesan yang hendak disampaikan oleh cerita rakyat tersebut. Adanya beberapa versi ini akan memperkaya tradisi lisan. Dalam konteks ini, kesedihan mendalam Fransiskus karena satu-satunya salib yang dia miliki, dan dia gunakan dalam kegiatan pewartaan iman telah hilang di laut. Tetapi kesedihannya itu tidak berlangsung lama, sebab salib yang telah hilang ditemukan kembali dibawa dari laut oleh kepiting/udang. Peristiwa ini bila dilihat secara akal sehat adalah merupakan hal yang tidak mungkin. Tetapi jika dilihat dalam perspektif iman, maka tidak ada yang tidak mungkin bagi Allah. Allah dapat melakukan apa saja, melampaui akal budi manusia. Pengalaman luar biasa Fransiskus ini mau mengajarkan bahwa Allah selalu hadir dan memberikan pertolongan kepada orang yang beriman kepada Allah, orang yang sangat mencintai dan dekat dengan Allah.

\section{Fransiskus Xaverius, Ajaran dan Pengaruhnya bagi Masyarakat Ambon}

Cerita mukjizat lain tentang Fransiskus peneliti temukan melalui studi pustaka buku Sejarah Gereja Katolik Indonesia Umat Katolik Awal Mula Abad XIV-XVIII, Ende-Flores, ditulis oleh M.P.M. Muskens, 1974. Buku tersebut menyatakan ketika Fransiskus singgah di Malaka, dia menyembuhkan orang yang sakit keras. Ibunya telah putus asa dan orang-orang telah meratapi dia seperti orang mati. Fransiskus dipanggil untuk mendengarkan pengakuan dosa orang sakit itu. Pater Fransiskus datang menyembuhkan anak itu dan menghibur ibunya. Setelah Fransiskus pergi, anak itu pun segera sadar dan sembuh ${ }^{23}$.

Berikutnya dijelaskan peristiwa Frasiskus mempertobatkan orang-orang yang hidup dalam keadaan berdosa di kampung

${ }^{23}$ (Muskens, 1974, p. 63) 
Nusaniwi. Mereka telah lama tidak melakukan pengakuan dosa. Berkat nasihat Fransiskus, mereka rela melepaskan selirnya dan hidup kembali dengan keluarga ${ }^{24}$. Ada juga orang yang telah belasan tahun hidup dalam kekerasan, pembunuhan, berhasil dipertobatkan oleh Fransiskus dan ia mau menerima sakramen pengakuan dosa ${ }^{25}$. Ada juga kesaksian lain dari Soveral de Fonseca, yang menyatakan bahwa kehadiran Fransiskus di kamp Portugis sangat dirasakan membawa berkat dan kedamaian bagi semua orang di sana. Biasanya terjadi perkelahian dan keributan di kamp. Teladan hidup yang gemilang, hidup suci, kewibawaan dan kotbahnya yang sangat menyentuh mampu mengubah suasana dan kehidupan orang-orang di kamp. Mereka semua sangat hormat dan mencintai dia. Tidak ada satu pun prajurit yang mengeluh tentang Fransiskus. Sebaliknya, semua orang merasa senang sekali dan sangat menghargainya ${ }^{26}$.

Kisah yang lain diceritakan tentang keberanian Fransiskus Xaverius pergi mengunjungi Pulau Moro. Pulau ini pada zamannya sangat ditakuti karena penduduknya dikenal tukang racun. Mereka memasukkan racun ke dalam makanan atar minuman takunya. Xaverius bertujuan menolong dan menyelamatkan jiwajiwa orang-orang kristen yang terlantar di sana. Tidak ada yang berani ke sana karena perilaku penduduknya. Para sahabatnya berusaha melarang dan menghalangi agar Fransiskus tidak pergi ke pulau itu. Namun tidak berhasil, dia bersikukuh tetap akan pergi. Para sahabatnya berusha memberi dia banyak obat penangkal atau penawar racun, tapi Fransiskus menolaknya. Dengan alasan bahwa pengharapan hanya kepada Allah, dan doa menjadi satu-satunya penangkal dan penawar racun. Dia meminta kepada sahabat-sahabatnya untuk mendoakan agar dia selamat dalam tugas karya kerasulannya di kepulauan yang berbahaya itu ${ }^{27}$.

Peristiwa lain yang sangat mengherankan diceritakan juga dalam buku sejarah gereja tersebut ketika Fransiskus sedang

\footnotetext{
${ }^{24}$ (Muskens, 1974, p. 130)

${ }^{25}$ (Muskens, 1974, p. 163)

${ }^{26}$ (Muskens, 1974, p. 131; 207-209)

${ }^{27}$ (Muskens, 1974, pp. 138-140)
} 
mempersembahkan Misa Kudus di kapel Santa Bunda Maria di Ternate. Sesudah kotbah, ketika mau persembahan, Fransiskus berkata: "Saudara-saudara, Joao de Araujo, yang tinggal di Amboina, sudah meninggal dunia". Araujo adalah sahabat Fransiskus. Umat terheran-heran, Fransiskus dapat mengetahui secara persis saat kematian sahabatnya itu tanpa ada yang memberitahukannya, sebab pada jaman itu belum ada telepon. Amboina jauhnya 90 mil dari Ternate, sedangkan waktu itu tidak ada kapal yang datang dari sana, sehingga dapat membawa berita kematian itu. Dua belas hari kemudian tibalah kapal yang membawa sepucuk surat untuk Pater Fransiskus tentang kabar kematian sahabatnya. Ketika orang-orang melihat surat itu dan jam meninggalnya, mereka semua bertambah heran dan semakin percaya kepada Pater itu. Tuhan telah memberitahukan dia secara ajaib saat kematian sahabatnya itu ${ }^{28}$.

Pengalaman-pengalaman luar biasa ini membuktikan bahwa Fransiskus Xaverius adalah orang yang luar biasa. Orang yang sangat dekat dengan Tuhan. Orang beriman dan penuh khidmat. Seluruh hidupnya dipersembahkan kepada Tuhan. Dengan menjadi misionaris, dia mewakafkan hidupnya untuk menyelamatkan jiwa-jiwa dan menolong sesama dan mewartakan injil ke penjuru dunia. Fransiskus telah menunjukkan teladan iman kepada dunia. Artinya orang yang percaya kepada Tuhan, mempercayakan seluruh hidupnya kepada Tuhan, dan setia kepada Tuhan, maka Tuhan Allah pasti akan melindungi, dan memberkati pekerjaannya sehingga berhasil, dan diterima oleh siapa saja. Dengan kata lain hidupnya akan menjadi saluran berkat kepada orang lain. Sebagaimana telah ditunjukkan oleh santo Fransiskus Xaverius, dia berkeliling kampung-kampung untuk mendoakan yang sakit, mengajarkan kebaikan, menolong siapa saja yang membutuhkan, mengenalkan Injil kepada siapa saja yang mau dan belum beragama.

Suri teladan dan kharisma Fransiskus membuat ia sangat dihormati oleh semua orang karena kata-kata dan pekerjaannya terutama karena seluruh sikapnya dan keunggulan pribadinya. Dalam hal ini dia memiliki suatu anugerah istimewa, yang mem-

${ }^{28}$ (Muskens, 1974, p. 168) 
buat orang sangat mudah mengikuti dia. Ia hidup penuh keutamaan seperti orang saleh. Ia hidup sederhana, bergantung pada derma-derma. Jika ada kelebihan padanya diberikannya kepada orang miskin. Di Maluku dia selalu sibuk mengajar agama Kristen kepada anak-anak dan wanita-wanita dan mendengarkan pengakuan dosa dan mentobatkan orang-orang yang tidak beriman, yang bisa ditariknya kepada agama Kristen. Semua orang memandang dia sebagai orang suci (wawancara, 19 Juni 2019).

Dari hasil wawancara dan analisis data maka ditemukan nilai-nilai yang diteladankan oleh Fransiskus Xaverius adalah religius, murah hati, sederhana, kerja keras. Dengan religius dimaksudkan nilai-nilai yang berhubungan dengan Tuhan. Misalnya beriman, beribadah, berdoa. Dalam hal ini penghayatan nilai religius sangat kental dalam kehidupan Fransiskus bahkan dapat dikatakan seluruh hidupnya merupakan sebuah ungkapan doa kepada Allah, ungkapan relasinya yang sangta dekat dengan Tuhan. Fransiskus setiap hari pergi berkeliling kampung untuk mengajar agama, mewartakan injil, mengenalkan Tuhan Allah kepada masyarakat baik anak-anak, remaja, dewasa dan orang tua, mendoakan orang sakit. Nilai berikutnya yang dapat dilihat dari kehidupan sang tokoh adalah kesederhanaan dan kemurahan hati. Fransiskus dengan mudah diterima dan disenangi oleh masyarakat salah satunya karena kebaikan dan kemurahan hati. Dia dengan cepat akan memberikan pertolongan kepada siapa saja. Apa yang ada padanya akan diberikan jika ada orang yang membutuhkan. Hal ini tampak dari cara hidupnya yang sangat sederhana bahkan sangat miskin. Dia tidur di balai-balai dari pelepah kelapa dan bantal tipis sekali dari kain katun yang hitam. Dia tidak mempunyai harta kekayaan.

Berdasarkan hasil wawancara dengan narasumber misionaris, Fransiskus selalu bersedia kapan saja jika ada orang yang meminta bantuan kepadanya, misalnya mengajar agama, mendoakan orang sakit dan mendengarkan pengakuan dosa. Terakhir, karakter lain yang dapat dicontoh dari kehidupan Fransiskus adalah kerja keras. Kerja keras adalah perilaku yang menunjukkan upaya sungguh-sungguh dalam mengatasi berbagai hambatan dalam tugas atau pekerjaan, serta menyelesaikan tugas 
dengan sebaik-baiknya. Semangat kerja keras Fransiskus tampak dalam aktivitasnya setiap hari. Sebagai seorang misionaris, agar dapat diterima dan dimengerti ajarannya, Fransiskus belajar bahasa lokal, dia juga setiap hari pagi siang dan malam berkeliling kampung-kampung untuk mengajar agama, mendoakan orang sakit dan mengunjungi siapa saja yang mungkin membutuhkan pertolongannya. Menurut narasumber, Fransiskus aktivitas kesehariannya berkeliling kampung-kampung, bertemu orang-orang, berdialog, berdiskusi, mengajarkan cara berdoa, mengajarkan kebaikan, mempertobatkan orang-orang yang belum mengenal Allah dalam hidupnya, membaptis, mendengarkan pengakuan dosa, dan mendoakan orang sakit. Hasil kerja kerasnya dapat dilihat sampai sekarang hidup, bertumbuh dan berkembang iman kekristenan di pulau rempah-rempah Ambon-Maluku.

Temuan studi ini mengonfirmasi studi terdahulu bahwa pentingnya melakukan studi mendalam terhadap cerita rakyat agar makna dan nilai yang tersembunyi dalam cerita tersebut memberikan inspirasi kreatif dan pemahaman sejarah yang kompleks ${ }^{29}$. Cerita rakyat Fransiskus jelas hadir dalam bingkai sejarah Maluku yang dahulu pernah menjadi kota perdagangan internasional. Sementara nilai-nilai yang telah diteladankan sang tokoh dapat menjadi inspirasi bagi manusia zaman sekarang. Misalnya nilai religius sangat penting dalam dunia modern saat ini. Orang cenderung terlena dengan godaan-godaan duniawi, lupa akan nilai-nilai rohani-spiritual sebagai penunjuk arah kehidupan manusia. Cerita rakyat religi ini mengingatkan bahwa manusia sebagai makhluk ciptaan Tuhan, tidak boleh lepas dari relasi dengan Sang Pencipta. Manusia harus ingat berdoa, beribadah, sholat agar hidupnya menjadi bernilai, bermakna dan tidak tersesat. Demikian juga nilai yang lain, yang terkandung dalam folkor ini, yaitu murah hati, sederhana, kerja keras. Saling menolong dengan peduli kepada sesama demi keselamatan bersama. Setiap orang pada hakikatnya hidup demi kebaikan dan keselamatan bersama. Dengan demikian sikap peduli kepada

${ }^{29}$ Jennifer Dos Reis Dos Santos, "Hidden Voices and Gothic Undertones: Slavery and Folklore of the American South," ETropic 18, no. 1 (2019): 108-24, https://doi.org/10.25120/etropic.18.1.2019.3672. 
sesama, mau berbagi dan bekerja keras merupakan sesuatu yang sangat dibutuhkan dalam kondisi kehidupan sosial saat ini. Dengan adanya wabah pandemi global COVID-19, nilai-nilai kehidupan tersebut sangat dibutuhkan agar semua dapat selamat melewati keadaan darurat saat ini. Dengan demikian sangat relevan dan aktual sekali mempelajari dan mengungkap nilai-nilai luhur kehidupan yang tersembunyi dalam cerita rakyat religi Maluku ini. Teladan tokoh Fransiskus dapat dijadikan sumber inspirasi dan pelajaran hidup untuk generasi sekarang.

Secara khusus bagi umat Katolik, Fransiskus Xaverius merupakan tokoh besar yang sangat dihargai karena jasa besar dalam mewartakan Injil dan menanamkan benih iman. Dia dikenal sebagai pionir misionaris Kristen dan oleh Paus Pius X digelari sebagai pelindung misi dan karya pewartaan iman. Selain sebagai seorang misionaris besar, dia dikenal juga seorang perunding dan duta terbaik karena karisma dan kemampuannya dalam berdialog-berkomunikasi. Namanya dikenal terus sepanjang masa karena teladan hidup dan karya-karya misinya. Untuk konteks Gereja Katolik Indonesia, secara khusus di Maluku, Santo Fransiskus merupakan tokoh besar, sangat berjasa dalam menciptakan kehidupan yang rukun, damai dan beriman. Hasil karya pewartaannya terus bertumbuh dan berkembang hingga saat ini. Kesalehan, cara hidup yang sederhana, sikap dan kebaikannya terhadap semua orang, nilai-nilai rohani yang dia teladankan membuat dia tetap dikenang dan tersimpan dalam memori masyarakat luas menjadi cerita rakyat Maluku.

Hal ini senada dengan yang telah ditunjukkan oleh Santos ${ }^{30}$ bahwa cerita rakyat sebagai warisan budaya yang berfungsi sebagai dasar untuk pengembangan budaya dan terus menjadi sumber tradisional kaya kreativitas, dan belajar tentang perjuangan leluhur mereka. Kisah St. Fransiskus menjaga tradisi tetap hidup karena diceritakan kembali dari generasi ke generasi dan merupakan sarana untuk menelusuri kembali warisan budaya sekaligus. Persoalan ini perlu pada saat sekarang ini karena banyak dari generasi muda bangsa Indonesia yang sudah melupakan

${ }^{30}$ Santos, 108-24. 
budaya yang merupakan warisan leluhur nenek moyangnya dan kebanggaan identitasnya. Hal ini juga merupakan upaya pelestarian cerita rakyat sebagai bagian dari kebudayaan baik perlindungan, pemanfaatan maupun pengembangan cerita rakyat di masa mendatang. Oleh karena itu studi cerita rakyat memberikan inspirasi yang menarik untuk dieksplor dan diekspos pada khalayak umum sebagai khasanah pengembangan ilmu budaya ${ }^{31}$. Selain itu juga menjadi sarana untuk pembelajaran, pembentukan karakter generasi muda. Hal ini sesuai dengan salah satu fungsi dan peran cerita rakyat, yaitu sebagai alat transmisi nilai, sikap, pengetahuan, pendidikan/pembelajaran dan ketrampilan yang perlu diwariskan dari setiap generasi ${ }^{32}$ Fungsi media pendidikan berperan sebagai alat bantu yang dapat merangsang pikiran, perasaan, perhatian, dan kemauan individu untuk terlibat dalam proses pembelajaran.

Hal yang umum terjadi dalam cerita rakyat adalah terdapat beberapa versi cerita. Perbedaan versi cerita rakyat ini merupakan konsekuensi dari sifatnya yang diwariskan turun temurun secara lisan ${ }^{33}$ sehingga sering terjadi interpolasi yakni perubahan atau pengembangan. Namun interpolasi yang terjadi tidak serta merta meninggalkan pola dasar yang sama $^{34}$. Hal ini terjadi dalam cerita rakyat religi ini. Ada dua versi yang menceritakan bahwa salib yang hilang di laut milik Fransiskus ditemukan dan diserahkan ke Fransiskus oleh seekor kepiting besar atau udang besar. Dalam hal ini yang terpenting adalah peristiwa besar yang luar biasa benar terjadi. Fransiskus adalah orang yang sangat mencintai Allah dan Allah menunjukkan kebaikan-Nya kepada

${ }^{31}$ Suwardi Endraswara, "Folklor Nusantara: Hakikat , Bentuk, Dan Fungsi," in Perpustakaan Nasional: Katalog Dalam Terbitan, ed. Suwardi Endraswara (Yogyakarta: enerbit Ombak Dua, 2013), 1-25, http://staff.uny. ac.id/sites/default/files/penelitian/dr-suwardi-mhum/folklornusantaradamicetak.pdf.

${ }^{32}$ Mufti, Ramazan, "Kearifan Lokal Dalam Folklor Asal Usul Kota Langsa," 88-95.

${ }^{33}$ Wiguna and Alimin, “Analisis Nilai-Nilai Moral Dalam Cerita Rakyat Kalimantan Barat," 143-58.

${ }^{34}$ Aditya Wardhani, "NILAI BUDAYA ETNIS BUGIS DALAM CERITA RAKYAT 'SI JAGO RENCANA' DI KABUPATEN SUMBAWA," Linguistik, Sastra Dan Pendidikan 2, no. 3 (2017): 1-16. 
dia. Bagi Allah tidak ada yang tidak mungkin selama orang beriman kepada Allah.

Kehidupan keseharian Santo Fransiskus di daerah Maluku sangat berkesan di hati masyarakat. Teladan hidupnya yang sangat sederhana, sikap peduli dan berbuat baik kepada setiap orang, hidupnya yang saleh, kesediaanya untuk menolong siapa saja dan setiap saat, cara pewartaannya yang sangat lembut, ramah dan penuh karisma serta peristiwa-peristiwa iman yang dia tunjukkan. Hal ini semua membuat dia sangat mudah diterima bahkan dicintai oleh masyarakat setempat. Peristiwa ini semakin memperteguh iman dan semangat Fransiskus dalam mewartakan iman. Bagi orang-orang pada masa itu peristiwa itu menumbuhkan iman kepercayaan kepada Allah. Pada saat yang sama juga menyadarkan mereka tentang siapa Fransiskus. Mereka menjadi semakin menghormati pribadi Fransiskus karena kesalehan dan kualitas pribadinya. Pada hakikatnya perbedaan versi tersebut dapat digunakan untuk memaksimalkan manfaat cerita rakyat sebagai bentuk pendidikan ${ }^{35}$. Sebab cerita yang digunakan secara tepat dalam pembelajaran akan membuat siswa bersemangat dan termotivasi untuk belajar. Cerita dapat membangun daya, imajinasi anak dan menumbuhkan kreativitas mereka dalam berpikir, berkata, dan berbuat ${ }^{36}$. Dalam konteks ini cerita rakyat perlu dilestarikan dan dikembangkan dalam rangka meningkatkan kecerdasan emosional bangsa ${ }^{37}$ dan didalamnya terkandung nilai-nilai religus, moral, etika, social yang sangat dibutuhkan dalam kehidupan manusia ${ }^{38}$.

\footnotetext{
${ }^{35}$ Mufti, Ramazan, "Kearifan Lokal Dalam Folklor Asal Usul Kota Langsa," 88-95.

${ }^{36} \mathrm{~N}$ M Ermadwicitawati, I N Sudiana, and I M Sutama, "Pengembangan Materi Ajar Cerita Anak Yang Mengandung Pendidikan Karakter Pada Pembelajaan Membaca Cerita Anak Smp Kelas Vii Di Singaraja," EJournal Program Pascasarjana Universitas Pendidikan Ganesha 2 (2013): 111 .

${ }^{37}$ Ni Putu Parmini, "Eksistensi Cerita Rakyat Dalam Pendidikan Karakter Siswa SD Di Ubud," Jurnal Kajian Bali 5, no. 2 (2015): 441-60.

${ }^{38}$ Linda Unsriana, "Nilai Kearifan Lokal Dalam Cerita Rakyat Jepang (Minwa)," Humaniora 4, no. 1 (2013): 310-17, https://doi.org/ 10.21512/ humaniora.v4i1.3441.
} 
Sejatinya cerita tentang Fransiskus ini merefleksikan bahwa orang yang mempunyai relasi yang sangat dekat dengan Tuhan, mempunyai iman yang teguh akan selalu diberkati, dilindungi dan membawa kedamaian kepada siapa saja. Dia akan memancarkan karisma dan menunjukkan keutamaan hidup dan nilai-nilai kerohanian yang kuat. Bahkan dia mampu melakukan hal-hal yang bagi manusia biasa hal tersebut sesuatu yang tidak mungkin. Namun, bagi Allah tidak ada yang tidak mungkin, tidak ada yang mustahil bagi Allah. Iman yang teguh, hidup saleh, melakukan kebaikan, kebenaran dan percaya kepada Allah menjadi elemen kunci. Hal ini semua telah dibuktikan oleh Santo Fransiskus selama hidupnya ketika berkarya sebagai seorang misionaris di Maluku. Dengan demikian, cerita tentang kesaksian hidup Santo Fransiskus ini tetap hadir, dikenang, dan diteruskan dari generasi ke generasi dan tidak terbatas dalam masyarakat Katolik saja. Cerita rakyat Fransiskus ini dikenal oleh masyarakat Maluku. Bahwa pernah ada seorang misionaris yang saleh, pewarta iman, hidupnya penuh kedamaian dan dirindukan oleh semua orang di Maluku. Fransiskus menunjukkan bahwa Allah itu ada, hidup, hadir dan mampu melakukan apa saja asal manusia mau percaya kepada-Nya.

\section{PENUTUP}

Fransiskus Xaverius misionaris eropa telah berhasil meletakkan fondasi kekristenan di kepulauan rempah-rempah. Sampai saat ini umat Katolik hidup bertumbuh dan berkembang sebagai buah karya misi Fransiskus. Tujuan utama Fransiskus hanyalah mewartakan kabar gembira (Injil) kepada orang yang belum mengenal Tuhan Allah. Cara pewartaannya yang lembut, membawa damai tanpa paksaan, hidup menyatu dan bersahabat dengan masyarakat lokal membuat dia mudah dan cepat diterima oleh penduduk setempat. Metode pewartaannya adalah berjalan keliling kampung bersama rombongan anak-anak, dengan membawa lonceng kecil yang dibunyikan sambil berjalan. Cara ini membuat penduduk dengan mudah mengenali kalau Fransiskus sedang lewat. Kepribadian, tutur katanya penuh hikmat, suri teladan dan charismanya yang kuat turut menambah daya tarik dan membuat orang kagum dan semakin menghormatinya. Apa- 
lagi kehidupannya memancarkan penghayatan nila-nilai: religius, murah hati, kerja keras, dan sederhana semakin memperkuat daya tarik terhadap orang lain untuk mengikuti ajarannya.

Akhirnya, teladan hidup Fransiskus yang saleh dan hidup dekat bersama Tuhan dengan berpegang teguh pada salib sebagai lambang kemenangan Kristus. Pekerjaannya sebagai pewarta iman diberkati Tuhan dan membuahkan hasil hingga sekarang bertumbuh iman akan Kristus di tanah Maluku. Teristimewa bagi masyarakat Katolik, dia merupakan utusan Allah, yang datang untuk memperkenalkan siapa Allah, memperkenalkan Tuhan Yesus yang selalu baik, berbuat yang benar, mewartakan cinta kasih terhadap semua orang. Fransiskus menunjukkan bahwa Tuhan itu dekat dengan manusia, Tuhan selalu hadir dalam pergulatan hidup manusia. Bahkan Tuhan mampu melakukan segalanya termasuk hal-hal yang mustahil bagi manusia. Kuncinya adalah hidup sederhana, peduli kepada sesama, berbuat yang baik dan benar, percaya pada Injil Tuhan dan selalu berpegang teguh dan mengandalkan Tuhan dalam seluruh pengalaman hidup. Salib tanda kemenangan Kristus selalu dibawa Fransiskus untuk menunjukkan bahwa dia dalam segala tugas dan karyanya bekerja bersama Tuhan, disemangati oleh salib Kristus yang telah menang mengalahkan maut. Dengan kata lain, Fransiskus menunjukkan bahwa hidup percaya pada Tuhan dan menghayati pengorban Kristus dalam Salib Suci menjadi modal rohani dan kekuatan Fransiskus untuk tidak takut melakukan kebenaran dan kebaikan terhadap siapa saja termasuk pada orang-orang jahat. Kesaksian hidup dan suri teladan Fransiskus memberikan pesan bahwa orang yang beriman kepada Allah mempunyai hubungan yang sangat dekat dengan-Nya. Hal ini akan terlihat dari cara hidupnya dan pekerjaannya akan berhasil karena diberkati Allah.

\section{DAFTAR PUSTAKA}

\section{Sumber Informan:}

Pastor Cornelis Johannes Böhm, MSC, Misionaris Belanda di Maluku

Dr. Asrif, M. Hum, Kepala Balai Bahasa Maluku 
Drs. M. Noor Tawainella, tokoh budaya Maluku

Dr. Wahidin, dosen Institut Agama Islam Negeri (IAIN) Ambon

Rm. Ignasius Refo, Rohaniawan Katolik, Dosen Sekolah Tinggi Pendidikan Agama Katolik (STPAK) St. Yohanes Penginjil Ambon

\section{Buku}

Creswell, John W. Research Design - Pendekatan Metode Kualitatif, Kuantitatif, dan Campuran. Yogyakarta: Pustaka Pelajar, 2018.

Danandjaja, James. Folklor Indonesia: Ilmu Gosip, Dongeng, dan lainlain. Jakarta: Pustaka Utama Grafiti, 1997.

Eliade, Mircea. Mitos: Gerak Kembali yang Abadi, Kosmos dan Sejarah. Yogyakarta: Ikon Teralitera, 2002.

H. Geurtjens MSC. Legenda-Legenda (penerjemah: C.J. Bohm, MSC), Yogyakarta: Sibuku Media, 2015.

Miles, Matthew B., dan A. Michael Huberman. Analisis Data Kualitatif. Jakarta: UI Press, 2009.

Muskens, Pr, Sejarah Gereja Katolik Indonesia: Umat Katolik Perintis 645-1500 Awal Mula Abad XIV - XVIII, Ende: Arnoldus, 1974.

Schumann, Olaf, Kekristenan di Asia Tenggara, Jakarta: BPK Gunung Mulia, 2017.

Berkhof, H. Sejarah Gereja. Disadur untuk Indonesia oleh Enklaar, I.H. Jakarta: BPK Gunung Mulia, 2019.

\section{Jurnal}

Agus Dody Purnomo, Toni Masdiono. "Menggali Khasanah Tradisi Lisan Ke Dalam Medium Visual." UNS, 2019. https://docplayer. info/171730949-Menggali-khasanah-tradisi-lisan-ke-dalammedium-visual.html.

Danandjaja, James. Folklor Indonesia: Ilmu Gosip, Dongeng, Dan Lain-Lain. Jakarta: Grafit, 1984.

Desi, Yundi, Larlen. "ANALISIS UNSUR INSTRINSIK CERITA RAKYAT SIGINDO KUNING DUSUN TUO MERANGIN JAMBI." FKIP Universitas Jambi, no. 5 (2018): 7-21.

Endraswara, Suwardi. "Folklor Nusantara: Hakikat, Bentuk, Dan 
Fungsi." In Perpustakaan Nasional: Katalog Dalam Terbitan, edited by Suwardi Endraswara,1-25. Yogyakarta: enerbit Ombak Dua, 2013. http://staff.uny.ac.id/sites/default/ files/ penelitian/drsuwardi-mhum/folklor-nusantaradamicetak.pdf.

Ermadwicitawati, N M, I N Sudiana, and I M Sutama. "Pengembangan Materi Ajar Cerita Anak Yang Mengandung Pendidikan Karakter Pada Pembelajaan Membaca Cerita Anak Smp Kelas Vii Di Singaraja." E-Journal Program Pascasarjana Universitas Pendidikan Ganesha 2 (2013): 1-11.

Finnegan, Ruth. Oral Literature in Africa . Cambridge: Open Book Publishers, 2012.

H. Geurtjens MSC. Legenda-Legenda, Terjemahan C.J. Bohm, MSC. Yogyakarta: Sibuku Media, 2015.

Hasan, Nita Handayani. Pelestarian Dan Pengembangan Mitos Ikan Lompa - Tinjauan Strukturlisme Levi Straus. Ambon: Kantor Bahasa Maluku Kementerian Pendidikan dan Kebudayaan, 2017.

Hasibuan, Nikmah Sari, Irman Puansyah, and Ahmad Yamin Hasibuan. "Anthropos : Jurnal Antropologi Sosial Dan Budaya ( Journal Analisis Cerita Rakyat Mandailing 'Sampuraga' : Suatu Kajian Pendekatan Objektif Dan Nilai Pendidikan Karakter Analysis of Mandailing Folklore " Sampuraga ": A Study of the Objective Approach An" 5, no. 2 (2020): 222-35.

Huberman, A. Michael, Matthew B. Miles, and J Saldana. Qualitative Data Analysis, A Methods Source Book. 3rd ed. USA: SAGE Publications, Inc., 2014.

Kanzunnudin, Mohammad. "CERITA LISAN DUA ORANG SUNAN BERADU JAGO DALAM KAJIAN STRUKTURAL DAN FUNGSI ALAN DUNDES." Bahasa Dan Sastra 3, no. 2 (2020): 235-48.

M.P.M. Muskens, Pr. Sejarah Gereja Katolik Indonesia - Umat Katolik Awal Mula Abad XIV - XVIII,. 1st ed. Ende-Flores: Arnoldus, 1974.

Mufti, Ramazan, Riyani. "Kearifan Lokal Dalam Folklor Asal Usul Kota Langsa." REFLEKSI EDUKATIKA 11, no. 1 (2020): 8895. https://doi.org/http://jurnal.umk.ac.id/index.php/RE. 
Parmini, Ni Putu. "Eksistensi Cerita Rakyat Dalam Pendidikan Karakter Siswa SD Di Ubud." Jurnal Kajian Bali 5, no. 2 (2015): 441-60.

Rahayu, Kanti. “ARTI PENTING FOLKLORE DAN TRADITIONAL KNOWLEDGE BAGI INDONESIA SEBAGAI ' THE COUNTRY OF ORIGIN."” media, 2000. https://media.neliti. com/ media/publications/241676-none-b4b826e4.pdf.

Santos, Jennifer Dos Reis Dos. "Hidden Voices and Gothic Undertones: Slavery and Folklore of the American South." ETropic 18, no. 1 (2019): 108-24. https://doi.org/10.25120/ etropic.18.1. 2019. 3672.

Syukria, Nina Siti Salmaniah Siregar. "Buku Cerita Si Kancil Dan Perilaku Meniru Siswa Taman Kanak-Kanak Syukria." Jurnal Seni Dan Budaya 2, no. 2 (2018): 90-102. http://jurnal. unimed. ac.id/2012/index.php/GDG.

Thompson, Kenneth. "Kenneth Thompson" 28, no. 2 (1980).

Trisni Andayani, Puspitawati, Juliarti. "ANTHROPOS : Jurnal Antropologi Sosial Dan Budaya Upaya Menebarkan Nilai-Nilai Kebaikan Melalui Pelatihan Mendongeng Bagi Siswa / I Sekolah Dasar Di Kecamatan Percut Sei Tuan" 3, no. 1 (2018): 61-68.

Unsriana, Linda. "Nilai Kearifan Lokal Dalam Cerita Rakyat Jepang (Minwa)." Humaniora 4, no. 1 (2013): 310-17. https://doi.org/ 10.21512/humaniora.v4i1.3441.

Wardhani, Aditya. "NILAI BUDAYA ETNIS BUGIS DALAM CERITA RAKYAT ' SI JAGO RENCANA' DI KABUPATEN SUMBAWA." Linguistik, Sastra Dan Pendidikan 2, no. 3 (2017): 1-16.

Wiguna, M zikri, and A A Alimin. "Analisis Nilai-Nilai Moral Dalam Cerita Rakyat Kalimantan Barat." Jurnal Pendidikan Bahasa 7, no. 1 (2018): 143-58. http://journal.ikippgriptk.ac.id/ index.php/ bahasa/article/view/833.

Youpika, Fitra, and Darmiyati Zuchdi. "Nilai Pendidikan Karakter Cerita Rakyat Suku Pasemah Bengkulu Dan Relevansinya Sebagai Materi Pembelajaran Sastra." Jurnal Pendidikan Karakter, no. 1 (2016): 48-58. https://doi.org/10.21831/ jpk. v0i1.10731. 